\title{
Size fractionation by suspension transport: a large scale flume experiment with shoaling waves
}

\author{
Brian Greenwood*, Zhiming Xu \\ Scarborough College Coastal Research Group, Division of Physical Sciences, \\ The University of Toronto at Scarborough, 1265 Military Trail, Scarborough, Ont., Canada M1C 1A4
}

Received 3 March 2000; accepted 23 March 2001

\begin{abstract}
Laboratory simulation of wave shoaling over a medium sand bed (mean size $=250 \mu \mathrm{m}$ ) for a range of wave conditions (a natural spectrum, symmetrical and asymmetrical wave groups) showed that a distinct horizontal fractionation of sediment by size occurred. Sediment became progressively coarser down-wave (onshore) from the test section and progressively finer up-wave (offshore) from the same source. This spatial sorting is explained by suspension transport alone and controlled by two factors: (a) a vertical profile of grain-size in the suspension, in which there is a distinct increase in the proportion of fines with elevation and a decrease in the mean size by approximately $18 \%$ between 0.04 and $0.24 \mathrm{~m}$; and (b) a vertical profile of the mean mass transport velocity, which revealed a down-wave (onshore) directed current close to the bed and a current reversal at higher elevations. The average elevation for the reversal was $\approx 0.14 \mathrm{~m}$ under the range of wave conditions simulated $\left(H_{\mathrm{s}}=0.22-0.78 \mathrm{~m} ; T_{\mathrm{pk}}=2.25-3.78 \mathrm{~s}\right)$. These two factors were enhanced by a frequency-dependent transport in the wave field. The primary waves produced a maximum net transport close to the bed, which was directed down-wave; at higher elevations as a response to a change in the phase coupling between concentration and velocity, the net transport was reversed. In contrast, the net transport associated with the group-bound long wave was directed up-wave at all elevations and the decay rate with elevation was significantly less than that associated with the primary waves. Thus, near the bed, transport by primary and secondary waves was roughly equal and opposite (resulting in little wave-induced net transport); at higher elevations, an up-wave transport by the secondary wave was dominant, complementing the net transport due to the mean current. (C) 2001 Elsevier Science B.V. All rights reserved.
\end{abstract}

Keywords: Size fractionation; Suspension transport; Shoaling groupy waves; Flume experiment

\section{Introduction}

It has long been recognized that on sandy shorefaces dominated by shoaling wind and swell waves, bed sediments with similar density increase in size from deep to shallow water in association with increasing local slope (e.g. Inman, 1953; Niederoda

\footnotetext{
* Corresponding author. Tel.: +1-416-287-7326; fax: +1-416287-7204.

E-mail address: greenw@scar.utoronto.ca (B. Greenwood).
}

et al., 1985; Guillen and Hoekstra, 1996, 1997; Hoekstra and Houwman, 1998). On the upper shoreface grain-size distributions tends to be more complex, reflecting local variations in bathymetry and the rapidly changing hydrodynamics associated with wave breaking and complex nearshore circulations, especially in association with bars (e.g. Fox et al., 1966; Greenwood, 1969; Mothersill, 1969; Greenwood and Davidson-Arnott, 1972. According to Cornaglia (1898) and Ippen and Eagleson (1955), size sorting across the shoreface profile reflects 
locations of oscillating equilibrium for a specific size, i.e. null points of net particle motion. In theory, large particles seaward, and small particles landward of the null points should move offshore and onshore respectively (for an excellent review see Johnson and Eagleson, 1966). A field test of these concepts by Miller and Zeigler $(1958,1964)$ produced mixed results, and as noted by Komar (1997) many of the predictions of the null point model have proved to be erroneous. Further, the model is based on the assumption that particles move as bedload; it is clear from a large number of recent field measurements (e.g. Sternberg et al., 1989; Hanes, 1991; Greenwood et al., 1990, 1991) that sediment suspension plays a major role in shoreface transport under waves and currents. More recent considerations of the grain size problem have been based upon Keulegan's (1948) proposal that the horizontal fractionation results from the down-wave (landward) transport of coarse bedload and up-wave (offshore) transport of fine suspended load over a rough boundary. Thus sediment fractionation may result from vertically stratified fluxes (see also Murray, 1967). Vincent and Green (1990), for example, document a case of vertically stratified sediment transport solely within the suspended load, with onshore transport close to the bed and offshore transport at higher elevations. In this case, fluxes were computed using virtually continuous measurements of sediment concentration within the lowest $1 \mathrm{~m}$ of the water column; $1 \mathrm{~cm}$ 'bins' of acoustic backscatter amplitude were coupled with modeled fluid velocities calibrated to measurements at $0.20 \mathrm{~m}$ above the bed. However, in order for size fractionation to occur, it is necessary to assume: (a) an upward-fining of grain size within the water column; and (b) a sediment transport system, in which coarser material moves landward closer to the bed and finer sediment moves in the opposite direction at higher elevations.

Existing field measurements are inconclusive with respect to grain size changes away from the bed. Measurements by Fairchild (1977) and Kana (1979) both illustrate a decrease in size between the bed and the suspended load and a decrease in the coarser fraction with increasing elevation within the surf zone. However, they do not reveal a significant consistent change in median diameter with elevation (see also the field measurements by Kennedy et al., 1981). More recently, Wang et al. (1998) used streamer traps (Kraus, 1987) to demonstrate a strong homogeneity in size and size-distribution with respect to distance vertically away from the bed, at least between $z=0.05$ and $0.50 \mathrm{~m}$. Over a rippled bed and under non-breaking waves, Nielsen (1983) showed a decrease in size between the suspended and bed material, but was unable to detect any significant difference in the mean grain size within the suspended load with elevation. Under similar conditions, Osborne and Greenwood (1993) noted a small $(18 \%)$ decrease in mean particle diameter between 0.04 and $0.50 \mathrm{~m}$ above the bed, with the most significant change being a marked increase in the relative proportion of the finest fractions. In such cases, onshore transport close to the bed should distribute more of the coarser sediment towards the shoreline and offshore transport at higher elevations should distribute more of the finer sediment towards deeper water.

Possible forcing mechanisms for size-sorting include: (a) an onshore fluid mass transport within the wave boundary layer and an offshore mass transport at mid-water depth (Longuet-Higgins 1953, 1956; Murray, 1967); (b) a near-bed velocity asymmetry (amplitude and duration) induced by wave shoaling (Cornish, 1898; Bagnold, 1940; Horn, 1992); (c) a setup-induced undertow and/or rip currents, which continue offshore from the breaker zone (Osborne and Greenwood, 1992a); and (d) a net transport induced by group-forced long waves (Shi and Larsen, 1981; Osborne and Greenwood, 1992b). Of critical importance to the sediment flux in a combined wave-current boundary layer over a rippled bed is the phase coupling between the extremely unsteady oscillatory velocity field at differing elevations and the vertically varying instantaneous sediment concentrations (Osborne and Greenwood, 1993; Greenwood et al., 1995).

In this paper we document results from a near prototype-scale laboratory experiment designed to determine the horizontal fractionation of sediment by size under a range of simulated waves by measuring the vertical structure of the: (a) bed and near-bed sediment size distributions; (b) near-bed velocity and sediment concentration; and (c) net fluxes of suspended sediment. Analyses of these measurements allows an investigation of the degree of sediment fractionation within the suspended load under shoaling, groupy 
waves alone and the components of transport (if any), which can account for the manner in which size fractionation occurred within the experimental design.

\section{Experimental design}

Wave simulation: the experiment was carried out in the large $(97 \times 2.0 \times 2.75 \mathrm{~m})$ wave research flume (WRF) of the National Research Council of Canada (Davies et al., 1994). A series of wave conditions was simulated in a constant mean water depth of $1.80 \mathrm{~m}$, for sampling periods of $\sim 17 \mathrm{~min}$ : (a) a 'natural' irregular wave spectrum, with significant heights $\left(H_{\mathrm{s}}\right)$ of $0.22-0.78 \mathrm{~m}$ and peak periods $\left(T_{\mathrm{pk}}\right)$ of $2.25-$ $3.46 \mathrm{~s}$; a total of 16 samples, (b) bichromatic waves, producing symmetrical wave groups of varying amplitudes and run-lengths $\left(H_{\mathrm{s}}=0.37-0.70 \mathrm{~m}\right.$; $T_{\mathrm{pk}}=2.55-3.78 \mathrm{~s}$ ); a total of 17 samples, and (c) 'snap shots' of asymmetrical wave groups (both positive, where the largest wave is towards the front of the group, and negative, where the reverse is true) selected from the field time series of irregular waves $\left(H_{\mathrm{s}}=0.37-0.70 \mathrm{~m} ; T_{\mathrm{pk}}=2.25-3.78 \mathrm{~s}\right) ;$ a total of 12 samples. The synthetic wave spectra were designed to evaluate the role of specific wave groups and group structures. Although these forms would clearly not form the total wave field in nature, the individual structures simulated were also recorded in the field.

The experiment was scaled as closely as possible to its lacustrine counterpart, the exception being its twodimensionality. In all cases, the Froude scaling factor was 1.7 , making these experiments near-prototype scale. The 'target' wave spectrum was actually recorded in the field, in similar water depths and with similar bedforms and grain size in the Canadian Great Lakes (Osborne and Greenwood, 1992b; Ollerhead and Greenwood, 1990). For this irregular wave spectrum, and using the root-mean-square oscillatory velocity and the equivalent sand grain roughness $\left[A_{\mathrm{b}} / k_{\mathrm{s}}\right.$; where $A_{\mathrm{b}}=$ near-bed fluid excursion amplitude, $k_{\mathrm{s}}=$ Nikuradse equivalent sand grain roughness], the laboratory wave Reynolds Numbers [ $\left(A_{\mathrm{b}} u_{\mathrm{b}}\right) / \nu$; where $A_{\mathrm{b}}=$ near-bed fluid excursion amplitude, $u_{\mathrm{b}}=$ near-bed fluid velocity, $\nu=$ kinematic viscosity] ranged from $0.43-2.35 \times 10^{5}$, with a relative grain roughness of $0.57-1.34 \times 10^{3}$. These values would place the wave boundary layer in the range of the regime of rough turbulent flow (Jonsson, 1966); Nielsen (1992, page 5) cites values of wave Reynolds Numbers greater than $10^{5}$ for field conditions. Equivalent measures of the wave Reynolds Number and relative grain roughness at the field site under nonbreaking waves were $0.75-12.8 \times 10^{5}$ and $0.77-$ $3.34 \times 10^{3}$ respectively. The laboratory data thus fall within the range of the field data and provide a convincing argument for similitude.

An examination of the cross-flume flows recorded by the flowmeters revealed values within the confidence band of the sensor. Thus, the flow field was essentially two-dimensional, with no evidence for cross-tank oscillations. The sensors were far enough away from the walls to eliminate any possibility of 'wall' effects, upon either the flow or the suspension. To limit reflection within the flume, which would clearly contaminate the target spectrum, three specific design features are important (Davies et al., 1994; Funke et al., 1980). First, a twin-actuator wave board generated the target spectrum; this allows the board to be used in either a flapper or piston mode. These two modes were automatically optimized to limit the generation of evanescent waves at the board itself. Further, the twin actuator wave board was equipped with a wave-height control mode, so that waves incident to the board (i.e. waves reflected from the rest of the flume) could be actively absorbed while a target spectrum is being generated. Finally, an extremely efficient expanded metal energy absorbing system was deployed at the downwave limit of the flume (Jamieson and Mansard, 1989). The reflected energy $(<5 \%)$ for the target spectra used was therefore negligible compared to the energy generated (see Davies et al., 1994 for further details). Thus no significant standing waves were generated, or any set-up induced return flows or any other steady flows such as rip currents or longshore currents as might be found in the real world. The sediment dynamics therefore reflect the role of shoaling, groupy waves over a near horizontal bed well outside of the surf zone, together with any secondary flows they may induce directly.

Waves and currents: wave height and period and the horizontal fluid velocity were determined respectively using (Fig. 1): (a) capacitance staffs; (b) electromagnetic current meters (Marsh-McBirney Inc., Models OEM512 and OEM523; the latter uses a 


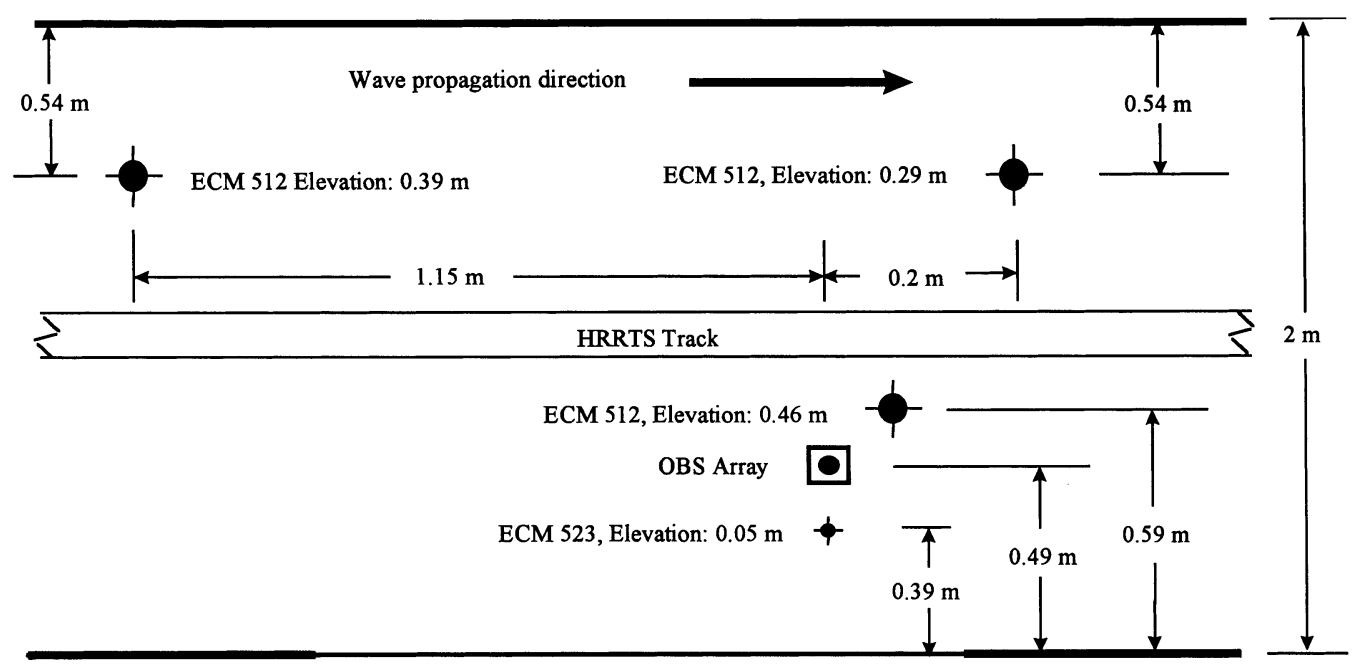

Observation area

Fig. 1. Plan view of the location of sensors within the test section. ECM= electromagnetic current meter; OBS = optical backscatterance suspended solids sensor; HRRTS = high-resolution remote tracking sonar. The large solid arrow indicates the direction of wave propagation.

$1.5 \mathrm{~cm}$ diameter sensor, which can be placed close to the boundary). The horizontal velocity was measured at an elevation of $z=0.05 \mathrm{~m}$ and at elevations ranging from $z=0.29$ to $z=0.46 \mathrm{~m}$.

Sediment concentration and size: the test section comprised a sub-horizontal pad $(7.0 \times 2.0 \times 0.2 \mathrm{~m})$ of medium $\left(m_{\phi}=2.00\right.$; i.e. $\left.250 \mu \mathrm{m}\right)$, well sorted $\left(s_{\phi}=0.45\right)$, slightly positively skewed $\left(\mathrm{sk}_{\phi}=\right.$ +0.17 ) sand, situated approximately $50 \mathrm{~m}$ from the wave paddle. The sand bed was essentially horizontal (or as close as it was possible to get in such a large sand pad), except at the upwave and downwave edges, where it sloped gently to merge with the flume floor. This is not exactly the same as natural conditions, although the part of the shoreface that it was to simulate has in general a very small slope. However, it is the slopes of the ripple faces that induce the local accelerations and flow separation, not the mean slope of the bed, and these angles are much larger. Thus, the simulation is appropriate for moderate waves on a near-horizontal surface, where bedforms are present.

Samples for determining the size-distribution of sediments suspended in the water column were obtained using hydraulic suction. Six stainless steel intake ports, $2.5 \mathrm{~mm}$ internal diameter and aligned vertically at $0.04 \mathrm{~m}$ intervals (starting at $z=$ $0.04 \mathrm{~m}$ ), were linked by tubes to a vacuum system; sample volumes of the order of 25-501 were collected with a flow rate at the nozzles of $0.88 \mathrm{~m} \mathrm{~s}^{-1}$. These samples reflect the immediate wave conditions.

Samples of bed material were also collected for grain size analysis from a number of locations during the experiments. Sample locations I and II were up-wave of the test section, location III was in the test section itself and another two sample locations, IV and V, were down-wave of the test section; the distance over which the samples were collected was approximately $22 \mathrm{~m}$. The sand samples collected both up-wave and down-wave of the test section reflected transported sand only, as there was no local bed material at these locations. Approximately $100 \mathrm{~g}$ were collected for analysis each time from the surface to a depth of approximately one centimetre at each location. These depth-integrated bed samples reflect the accumulation of sediment over the whole experimental period. The filtered suspended solids and bed samples were analysed by dry sieving (see Syvitski, 1991 for recent reviews of the method), using eightinch sieves at $1 / 4 \phi$ intervals between 0.5 and $4.00 \phi$; they were shaken for $10 \mathrm{~min}$ in a Ro-Tap shaker. 
Settling velocities for some of the samples were also determined; however, a number of problems exist with interpretation (e.g. shape controlled settling; settling delay due to large concentrations; wake-effect on smaller particles by larger particles; see Nielsen, 1992). The preferred estimate of actual mass distribution for samples of these well-rounded Ottawa Sands was sieve analysis; these analyses are presented in this paper.

Continuous records of suspended sediment concentration at a number of elevations above the bed $(z=0.04,0.08,0.12,0.16,0.20,0.24 \mathrm{~m})$ were obtained using optical backscatterance suspended solids sensors (Model OBS-1P; D and A Instruments Company, OBS ${ }^{\mathrm{TM}}$; Downing et al., 1981). These sensors were calibrated in a vertical sediment re-circulating facility using the test sediment (see Black and Rosenberg, 1994; Greenwood and Jagger, 1995). The lowest measurement elevation for concentration was nominally at $z=0.04 \mathrm{~m}$. The bedload was not measured in this experiment as currently there is no instrument capable of measuring the instantaneous bedload transport. The results will therefore only apply to suspension transport.

Bedforms: the bed geometry generated by each wave state was determined using a high resolution remote tracking sonar (HRRTS III; Greenwood et al., 1993), which uses a unique phase synchronization and detection technique (Richards and Greenwood, 1993) to detect the immobile scatterers of the real bed. It records a two-dimensional, $2 \mathrm{~m}$ long profile, which can then be analysed for ripple height, spacing, steepness, asymmetry, etc.

Data acquisition: the sensors were deployed in the configuration illustrated in Fig. 1. Single data sets consisted of signals recorded at a sampling rate of $20 \mathrm{~Hz}$ for the full sampling period of $\sim 17 \mathrm{~min}$. Data were recorded using GEDAP (Funke et al., 1980; Miles, 1990), an integrated software package for experimental control and data acquisition. In this paper, data from the station with the two electromagnetic current meters at $z=0.05$ and $0.29 \mathrm{~m}$ will be used extensively.

\section{Profiles of sediment concentration and grain size}

Vertical profiles of the time-averaged, suspended
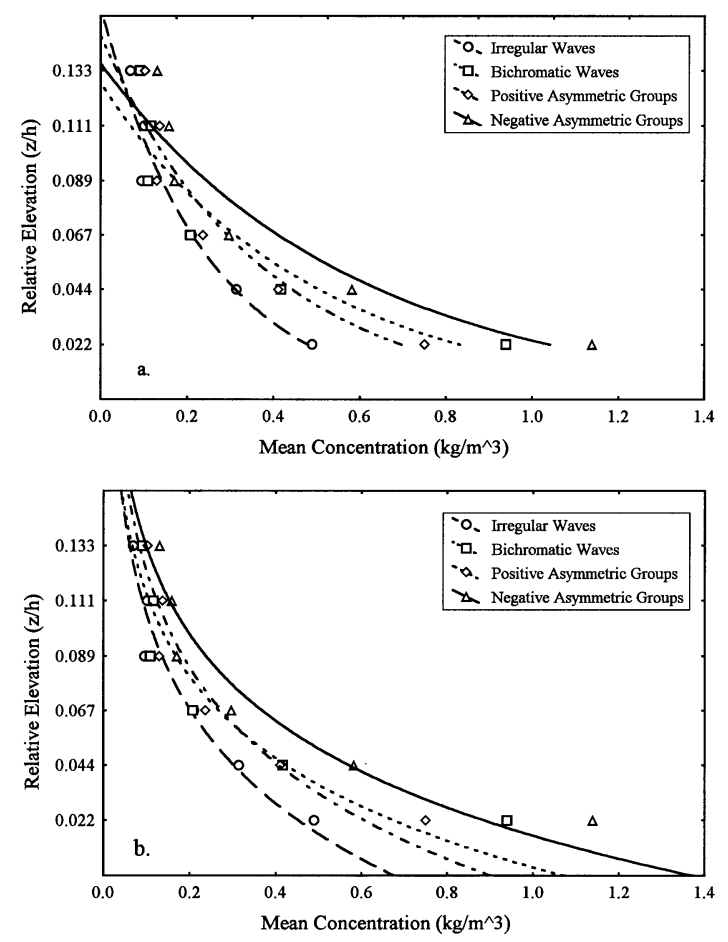

Fig. 2. Time-averaged suspended sediment concentration profiles for the largest wave condition for each wave type simulated: irregular waves, bichromatic waves (symmetrical groups) and positive and negative asymmetrically grouped waves. A logarithmic function is fitted to the data in (a) and an exponential function is fitted in (b).

sediment concentration were computed from the optical backscatter records for each of 44 data sets (16 irregular wave simulations, 17 bichromatic simulations (symmetrical wave groups), 12 asymmetric wave groups) by simply averaging the instantaneous values for each $17 \mathrm{~min}$ record (Fig. 2). As expected from previous work (e.g. Skafel and Krishnappan, 1984; Vincent and Green, 1990; Nielsen, 1992; Osborne and Greenwood, 1993; Lee and Hanes, 1996; Williams et al., 2000) mean concentrations decrease non-linearly away from the bed, regardless of the wave type, the group structure or the energy level. The profiles illustrated were measured under the largest waves associated with the irregular wave spectrum, bichromatic waves (producing symmetric wave groups) and repeated snapshots of positive and negative asymmetric wave groups. It is evident that concentrations are smallest under irregular waves; 


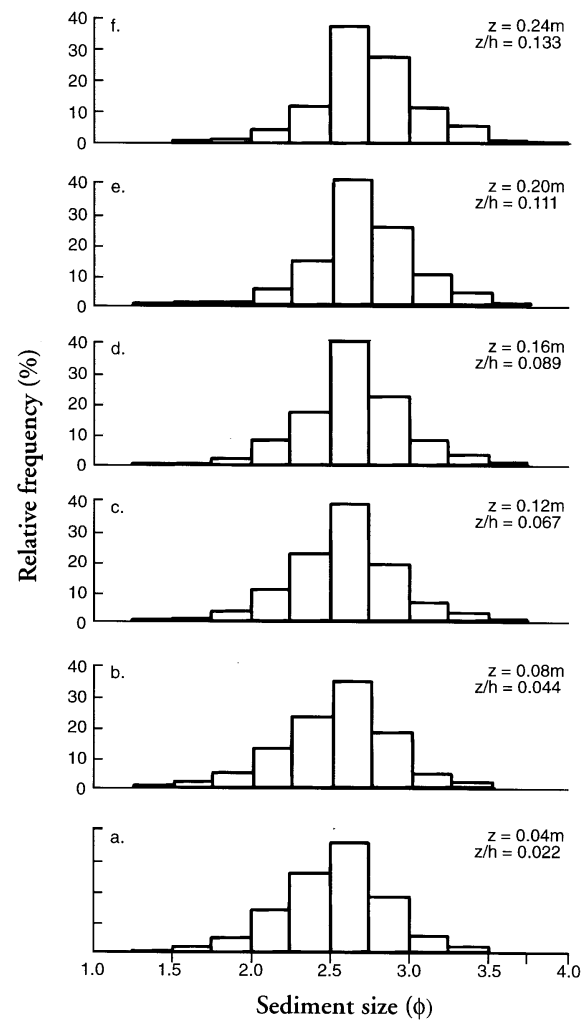

Fig. 3. Size-distributions within the suspended load at increasing elevations above the bed; the lowest panel is at $z=0.04$ and the highest panel is at $z=0.24 \mathrm{~m}$. Note: $\phi=-\log _{2}$ \{diameter in $\mathrm{mm} /$ diameter of a $1 \mathrm{~mm}$ standard\}, after McManus (1963). the largest concentrations (by a factor of 2) are associated with the snapshots of negative asymmetrical wave groups. While a logarithmic function appears to provide a closer fit at lower elevations, the exponential function was better at higher elevations. However, as noted previously (e.g. Osborne and Greenwood, 1993) no clear statistical distinction can be made between the two theoretical models in terms of best fit. Nevertheless, since concentration magnitudes are much larger near the bed, the logarithmic function is preferred. A more recent study by Green and Black (1999) suggests that a useful way of evaluating the profile would be to divide it into two layers, depending upon the bed configuration.

While the time-averaged suspended sediment concentrations exhibited a predictable decay with elevation, the vertical distribution of the time-averaged grain-size was more complex (Fig. 3 and Table 1). The distributions illustrated were those determined from the suction samples collected during the bichromatic (symmetrical wave groups) wave simulations. At this time the bed was covered by 2 to 3 -dimensional oscillatory ripples depending on the wave energy (Fig. 4a and b); the average ripple height $(\eta)$ was $0.023 \mathrm{~m}$, spacing $(\lambda)$ was $0.170 \mathrm{~m}$ and the ripple steepness $(\eta / \lambda)$ was 0.13 . Vortex shedding from these steep ripples was clearly evident by direct observation through the side-windows of the test section. The time-averaged mean grain size for the six samples was $2.37 \phi(193 \mu \mathrm{m})$; since the average size of the bed material was $2.00 \phi(250 \mu \mathrm{m})$, this is a significant reduction (by $\sim 18 \%$ ). Within the water column there

Table 1

Grain-size statistics for suspended sediment (Samples 4 and 5) and test (bed) sand

\begin{tabular}{|c|c|c|c|c|c|c|c|c|}
\hline \multirow{2}{*}{$\begin{array}{l}\text { Elevation } \\
(\mathrm{m})\end{array}$} & \multicolumn{2}{|l|}{ Mean } & \multicolumn{2}{|c|}{ Standard deviation } & \multicolumn{2}{|l|}{ Skewness } & \multicolumn{2}{|l|}{ Kurtosis } \\
\hline & $\begin{array}{l}\text { Sample } 4 \\
\left(\mathrm{~m}_{\phi}\right)\end{array}$ & $\begin{array}{l}\text { Sample } 5 \\
\left(\mathrm{~m}_{\phi}\right)\end{array}$ & $\begin{array}{l}\text { Sample } 4 \\
\left(\mathrm{~s}_{\phi}\right)\end{array}$ & $\begin{array}{l}\text { Sample } 5 \\
\left(\mathrm{~s}_{\phi}\right)\end{array}$ & $\begin{array}{l}\text { Sample } 4 \\
\left(\mathrm{sk}_{\phi}\right)\end{array}$ & $\begin{array}{l}\text { Sample } 5 \\
\left(\mathrm{sk}_{\phi}\right)\end{array}$ & $\begin{array}{l}\text { Sample } 4 \\
\left(\mathrm{k}_{\phi}\right)\end{array}$ & $\begin{array}{l}\text { Sample } 5 \\
\left(\mathrm{k}_{\phi}\right)\end{array}$ \\
\hline 0.24 & 2.48 & 2.49 & 0.34 & 0.33 & 0.16 & -0.03 & -2.56 & -2.57 \\
\hline 0.20 & 2.45 & 2.44 & 0.33 & 0.33 & 0.14 & -0.20 & -2.50 & -2.54 \\
\hline 0.16 & 2.40 & 2.39 & 0.34 & 0.33 & -0.03 & -0.08 & -2.52 & -2.55 \\
\hline 0.12 & 2.36 & 2.33 & 0.33 & 0.33 & -0.01 & -0.19 & -2.55 & -2.55 \\
\hline 0.08 & 2.32 & 2.27 & 0.35 & 0.36 & -0.15 & -0.39 & -2.53 & -2.52 \\
\hline 0.04 & 2.29 & 2.27 & 0.35 & 0.35 & -0.14 & -0.27 & -2.50 & -2.52 \\
\hline Average & & 2.37 & & 0.34 & & -0.10 & & -2.53 \\
\hline Test sand & & 2.00 & & 0.45 & & 0.17 & & -2.38 \\
\hline
\end{tabular}




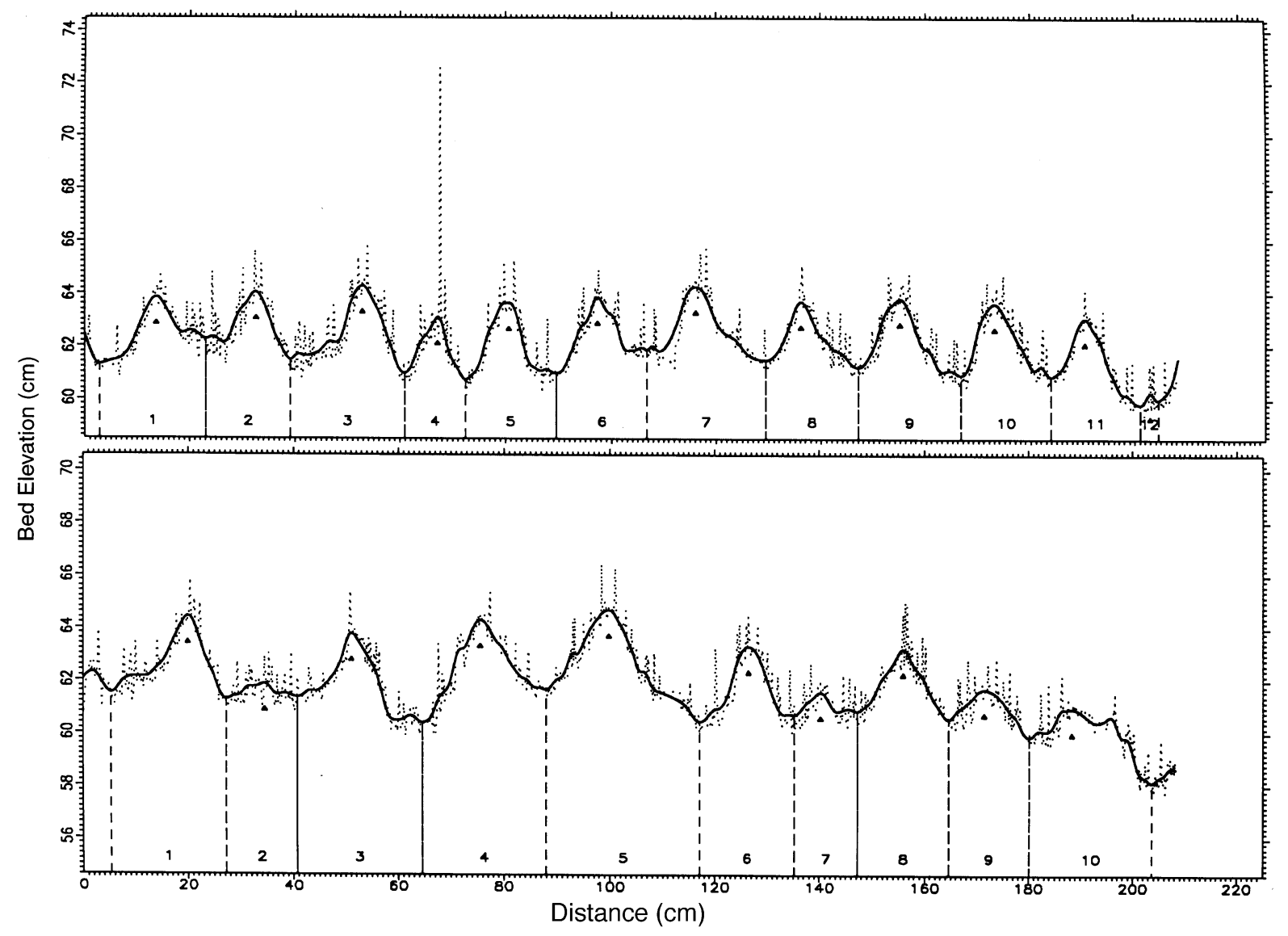

Fig. 4. Sonar profiles of the sand bed during bichromatic wave simulations: (a) 2-dimensional oscillation ripples, $(\eta=0.025 \mathrm{~m}, \lambda=0.173 \mathrm{~m})$; $H_{\mathrm{s}}=0.37 \mathrm{~m}, T_{\mathrm{pk}}=3.25 \mathrm{~s}$; (b) 3-dimensional oscillation ripples, $(\eta=0.023 \mathrm{~m}, \lambda=0.194 \mathrm{~m}) ; H_{\mathrm{s}}=0.56 \mathrm{~m}, T_{\mathrm{pk}}=3.25 \mathrm{~s}$. A simple algorithm defines the crests (small triangles) and troughs (dotted line), the number of bedforms and the associated bedform heights and spacing, as well as computing the ripple indices. Wave propagation is from right to left.

was a small but detectable decrease in grain size with elevation: for example at $z=0.04 \mathrm{~m}, m_{\phi}=2.28$ $(206 \mu \mathrm{m})$, and at $z=0.24 \mathrm{~m}, m_{\phi}=2.49(178 \mu \mathrm{m})$. This change of approximately $10 \%$ did not, however, result from a significant shift in the modal class, which remained at 2.50-2.75 $\phi(149-177 \mu \mathrm{m})$. Rather there was a preferential addition of fines at increasing elevations. Furthermore, only at the highest elevation was there any noticeable loss of the coarsest fraction (1.25-1.50 $\phi$; see Fig. 3), although there was a progressive reduction in the $1.50-2.50 \phi$ class. This shift was reflected in vertical changes in the grain-size skewness. The negative skewness commonly associated with the size-distributions of wave-transported sediment (e.g. Greenwood, 1969) is evident in the sands suspended immediately above the bed; at $z=$ $0.04-0.08 \mathrm{~m}$, the skewness averaged -0.24 , while the bed sediment was positively skewed $(+0.17)$. The negative skewness decreased to values of +0.02 (at $z=0.20-0.24 \mathrm{~m}$, making the distribution essentially symmetric or positively skewed at this elevation (Table 1). Both Nielsen (1983) and Osborne and Greenwood (1993) have reported the relative increase in the fine fraction with elevation previously from field measurements. While the values for kurtosis decreased between the bed and the suspended load, the difference was small (Table 1) and values were essentially constant within the suspension load. 

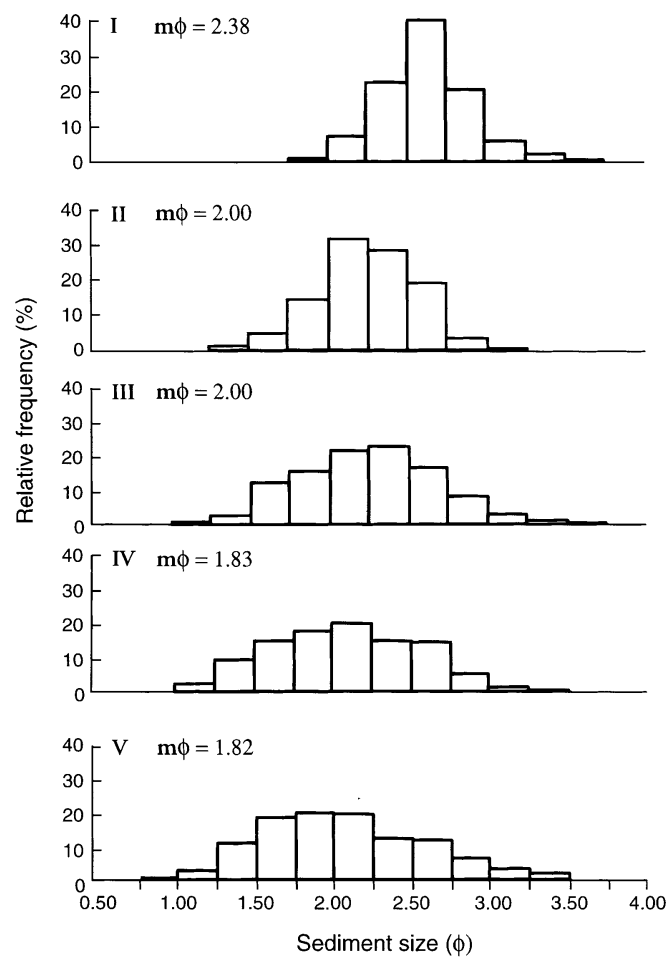

Fig. 5. Size-distributions of samples collected along the flume from the up-wave section (I and II), to the test section (III), to the downwave section (IV and V). The samples I-V are respectively 40, 45, 50,57 and $63 \mathrm{~m}$ away from the wave board.

Thus, there was little loss, if any, of the coarsest fractions per se (except between the bed itself and the water column), while there was a marked upward increase of fines. This observation supports the view that suspension involves two mechanisms: (a) convective transport by separation vortices as they are ejected from the rippled bed; in this case there is little or no separation by size as the vortices rise; (b) diffusion transport as a result of the decreasing concentration upwards from the bed which will continually pump fines higher into the water column (see also comments by Nielsen, 1992).

Besides the variation of size within the suspended load, there was a marked spatial variation in the grainsize of the accumulated (re-activated/transported) bed material. Fig. 5 illustrates the size-distributions of bed samples collected from the five locations positioned sequentially in the down-wave direction and Table 2 summarizes the grain-size statistics. Samples I and II (Fig. 5) were collected respectively at $9 \mathrm{~m}$ and $5 \mathrm{~m}$ up-wave of the centre of the test section. Sample III (Fig. 5) was collected from the centre of the test section itself, and another two samples, IV and V (Fig. 5) were taken $7 \mathrm{~m}$ and $13 \mathrm{~m}$ down-wave from the centre of the test section. The total distance was $22 \mathrm{~m}$. Samples II and IV were collected from sections of the flume close to the test section where significant sediment accretion had occurred and the flume bed was fully covered by sand and exhibited 3-dimensional, oscillation cross-ripples at the time of sampling. Samples I and V were collected at greater distances both up-wave and down-wave, where the floor of the flume was not yet fully covered by sediment and 'starved', 2-dimensional, oscillation ripples were present. These samples were collected following a two-day series of simulations of positive and negative asymmetrical wave groups.

Examination of the size-distributions (Fig. 5; Table 2) reveals that: (a) average particle size increased in a progressive manner from the furthest up-wave (offshore) location to the furthest down-wave (onshore) location; $m_{\phi}$ changed from 2.38 to 1.82 $(192-283 \mu \mathrm{m})$, an increase of about $24 \%$ over a horizontal distance of $22 \mathrm{~m}$; (b) the modal class also shifted significantly; the percentage in the finest

Table 2

Grain-size statistics for bed samples

\begin{tabular}{llllcl}
\hline Station & $\begin{array}{l}\text { Distance } \\
(\mathrm{m})\end{array}$ & $\begin{array}{l}\text { Mean } \\
\left(\mathrm{m}_{\phi}\right)\end{array}$ & $\begin{array}{l}\text { Standard deviation } \\
\left(\mathrm{s}_{\phi}\right)\end{array}$ & $\begin{array}{l}\text { Skewness } \\
\left(\mathrm{sk}_{\phi}\right)\end{array}$ & $\begin{array}{l}\text { Kurtosis } \\
\left(\mathrm{k}_{\phi}\right)\end{array}$ \\
\hline I & 9.3 & 2.38 & 0.29 & 0.20 & -2.67 \\
II & 5.2 & 2.00 & 0.31 & -0.12 & -2.66 \\
III & 0.0 & 2.00 & 0.45 & 0.17 & -2.38 \\
IV & 7.2 & 1.83 & 0.46 & 0.08 & -2.46 \\
V & 12.6 & 1.82 & 0.52 & 0.40 & -2.27 \\
\hline
\end{tabular}


modal class $\phi=2.50-2.75 \quad(149-177 \mu \mathrm{m}) \quad$ was gradually reduced from location I (furthest up-wave) to the location $\mathrm{V}$, while the percentage in the coarsest modal class, $\phi=1.75-2.00(297-250 \mu \mathrm{m})$ was progressively increased in the down-wave direction from its furthest up-wave location; (c) the fraction of fines in the distributions increased progressively in the up-wave direction away from the test section and decreased in the down-wave direction. For example, the percentage of material finer than $\phi=$ $3.5(88 \mu \mathrm{m})$ increased from $0.135 \%$ at the test section (location III) to $0.240 \%$ at location II to $0.320 \%$ at the location I furthest up-wave, (d) the coarse fraction $(\phi<1.00)$ also exhibited a spatially consistent pattern, increasing down-wave from the test section and decreasing up-wave; the percentage of this coarse fraction was only $0.026 \%$ at location I, increasing progressively to $3.040 \%$ at location $\mathrm{V}$.

These results support the generally held view that fractionation by size does occur under shoaling waves, and that during transport the resulting sediments coarsen down-wave (onshore) and fine upwave (offshore). Since sand accumulated in areas of the flume where no sand existed before, the size characteristics of these sediments must reflect the transported load alone; the samples could not be mixed with the test material. Fractionation within the suspended load also supports previous findings in two ways: (a) the suspended sediment was significantly finer than the bed material; (b) there was an increasing addition of fines with elevation. However, a distinct and consistent decrease in the mean size with elevation was identified. The question remains as to the mechanisms responsible for the transport of these fractionated sediments up-wave and down-wave.

\section{Components of sediment transport}

For the controlled wave simulations described, the near-bed flow field and associated suspended sediment transport rates can be separated into three components: (a) a high frequency oscillatory transport induced by the primary waves; (b) a low frequency oscillatory transport induced by the group-bound long wave; and (c) a quasi-steady mean current transport induced by mass transport resulting from the shoaling of the high frequency waves. The time and depth-integrated mean, $\left\langle q_{\mathrm{s}}\right\rangle_{\text {mean }}$, and oscillatory, $\left\langle q_{\mathrm{s}}\right\rangle_{\mathrm{osc}}$, transport components can be defined (after Huntley and Hanes, 1987):

$$
\begin{aligned}
& \left\langle q_{\mathrm{s}}\right\rangle_{\text {mean }}=\frac{1}{T}\left\{\int_{0}^{T} \int_{0}^{h} U_{(z, t)}\right\} \times \frac{1}{T}\left\{\int_{0}^{T} \int_{0}^{h} C_{(z, t)}\right\} \\
& \left\langle q_{\mathrm{s}}\right\rangle_{\mathrm{osc}}=\frac{\Delta f}{f_{\mathrm{c}}} \int_{0}^{T} \int_{0}^{h} C_{(\mathrm{uc})}(f)
\end{aligned}
$$

where $U_{(z, t)}=$ instantaneous velocity at time $t$, at elevation $z\left(\mathrm{~m} \mathrm{~s}^{-1}\right) ; C_{(z, t)}=$ instantaneous concentration at time $t$, at elevation $z\left(\mathrm{~kg} \mathrm{~m}^{-3}\right) ; C_{(U C)}=$ co-spectrum of the instantaneous horizontal velocities and concentrations; $f=$ frequency band of a specific oscillation $(\mathrm{Hz}) ; \Delta f=$ bandwidth for spectral estimates; $f_{\mathrm{c}}=$ frequency range; $T=$ time of integration (s); $h=$ water depth (m). The high and low frequency components of transport were determined from arbitrary cut-offs between the two bands.

With velocity measurements at only two elevations, $z=0.05$ and $0.29 \mathrm{~m}$, the question arises as to the nature of the velocity structure between. Models exist which predict such a velocity structure over a rough bed (e.g. Grant and Madsen 1979; 1982), but are not yet completely validated. As there was no detectable phase shift in velocity between these two elevations, at least at the sampling frequency used in this experiment $(20 \mathrm{~Hz})$, as a first approximation a simple linear interpolation of velocity between the two elevations was used.

\section{Wave-induced suspended sediment transport}

To examine the simplest case of transport associated with the primary wave and a second order, group-bound long wave, measurements recorded under the symmetrical wave groups were analysed in detail. Fig. 6a illustrates a typical spectrum of the horizontal velocity $(z=0.29 \mathrm{~m})$ for the most energetic bichromatic wave condition $\left(H_{\max }=0.70 \mathrm{~m}\right)$, together with the associated cospectra between concentration and velocity for each elevation from $z=0.04$ to $0.24 \mathrm{~m}$. The horizontal velocities were adjusted for elevation prior to the cross-spectral analysis. The bed at this time was composed of 3dimensional, oscillation cross-ripples; average ripple 

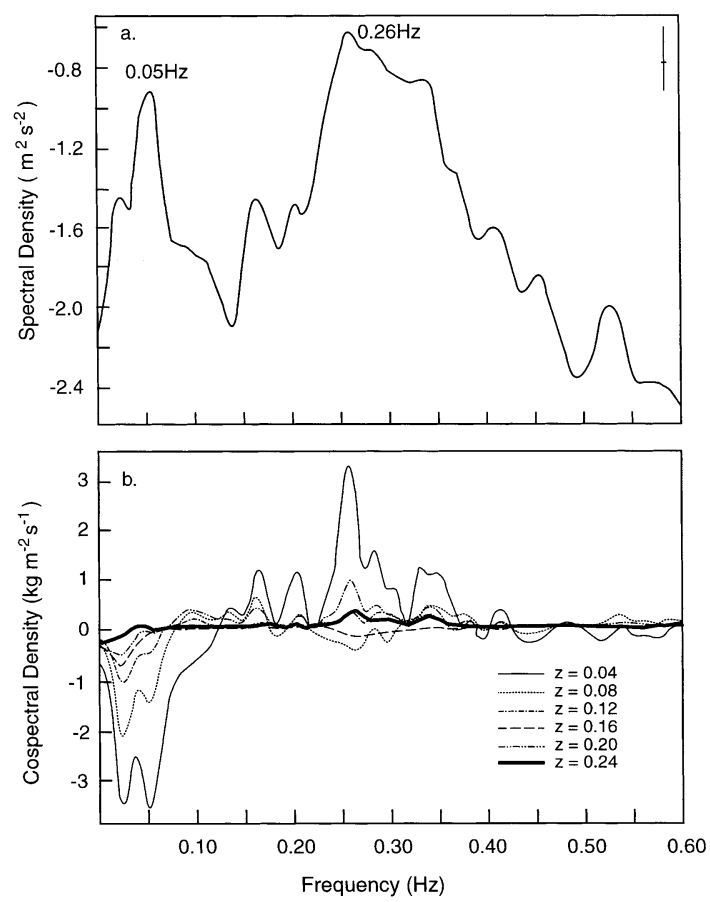

Fig. 6. The horizontal velocity spectrum at $z=0.29 \mathrm{~m}$ (a) and cospectra (b) recorded at a range of elevations for the full, irregular wave spectrum with maximum wave height. The vertical solid line represents the 95\% confidence band around the spectrum. The cospectra were computed using the interpolated velocities for elevations between 0.04 and $0.24 \mathrm{~m}$. Note: $H_{\mathrm{s}}=0.57 ; T_{\mathrm{pk}}=3.85 \mathrm{~s}$; bedforms were 3-dimensional cross-ripples: $\eta=0.022 \mathrm{~m} ; \lambda=$ $0.169 \mathrm{~m} ; \eta / \lambda=0.13$.

height $(\eta)$ was $0.023 \mathrm{~m}$, and average spacing $(\lambda)$ was $0.198 \mathrm{~m}$, for an average steepness of $(\eta / \lambda)$ of 0.116 .

At the primary wave frequency $(\sim 0.15-0.50 \mathrm{~Hz})$, suspended sediment transport was directed downwave close to the bed (positive co-spectral densities), but decreased rapidly with elevation (Fig. 6b); this in part reflects the extremely rapid decrease in concentration with elevation. A reversal in the direction of transport at the primary frequency occurred at some elevation (in this specific case above $z=0.08 \mathrm{~m}$ ) and then a down-wave transport was again evident at the highest elevations $(z=0.20$ and $0.24 \mathrm{~m})$. The co-spectral peaks were all significant at $\alpha=0.05$ (Davidson et al., 1993), except for the uppermost measurement elevation $(z=0.24 \mathrm{~m})$, where there were no significant co-spectral densities at any frequency. The group-bound long wave $(<0.15 \mathrm{~Hz}$;
$T_{\mathrm{pk}}=0.05 \mathrm{~Hz}$ ) induced an up-wave suspended sediment transport (negative co-spectral densities) at all elevations and the co-spectral densities were as large, if not larger, than those of the primary wave at all elevations. Furthermore, transport rates at these lower frequencies decreased more gradually with increasing elevation and, under these particular energy levels, a transport reversal was never recorded. Therefore, it would appear that there was a more rapid de-coupling between concentration and velocity with elevation at the higher frequencies. This reflects, at least in part, the fact that the high frequency oscillations are coupled directly to the entrainment process, and thus to the separation vortices, shed each half-wave cycle from the rippled bed; these sediment laden vortices change very rapidly both spatially and temporally (Xu, 1998). In contrast, the long wave is coupled to 'suspension events' (Greenwood et al., 1990, 1991), where there is a coherent enhancement of the sediment concentration field and a more gradual increase and decrease in suspended sediment at the scale of the long wave during the passage of a wave group (see also $\mathrm{Xu}, 1998$ ).

Fig. 7 illustrates the co-spectra from another bichromatic simulation (Fig. 7a), together with co-spectra from positive and negative asymmetrical wave groups (Fig. $7 b$ and c). The down-wave transport at the primary wave frequency and up-wave transport by the group-bound long wave is again evident. Since all of these simulations were at the maximum wave height, it is important to note the magnitudes of the transport. While primary wave transports were roughly of the same scale for both the symmetrical and positive asymmetrical wave groups (Fig. $7 \mathrm{a}$ and b; $2 \mathrm{~kg} \mathrm{~m}^{-3} \mathrm{~s}^{-1}$ ), the long wave transport by the asymmetrical wave groups was clearly larger, by at least a factor of 2 . This results from a subtle flux coupling between the largest wave and its position within a group and the phase of the second order long wave (see Xu, 1998).

Analyses of all datasets revealed that, except for the very smallest wave energies, close to the bed the primary waves induced large down-wave suspended sediment transport rates; this transport decreased rapidly with elevation and in some cases was reversed. The horizontal velocity and sediment concentration fields seem totally uncoupled (giving near-zero net transport) above about $0.14-0.16 \mathrm{~m}$; 

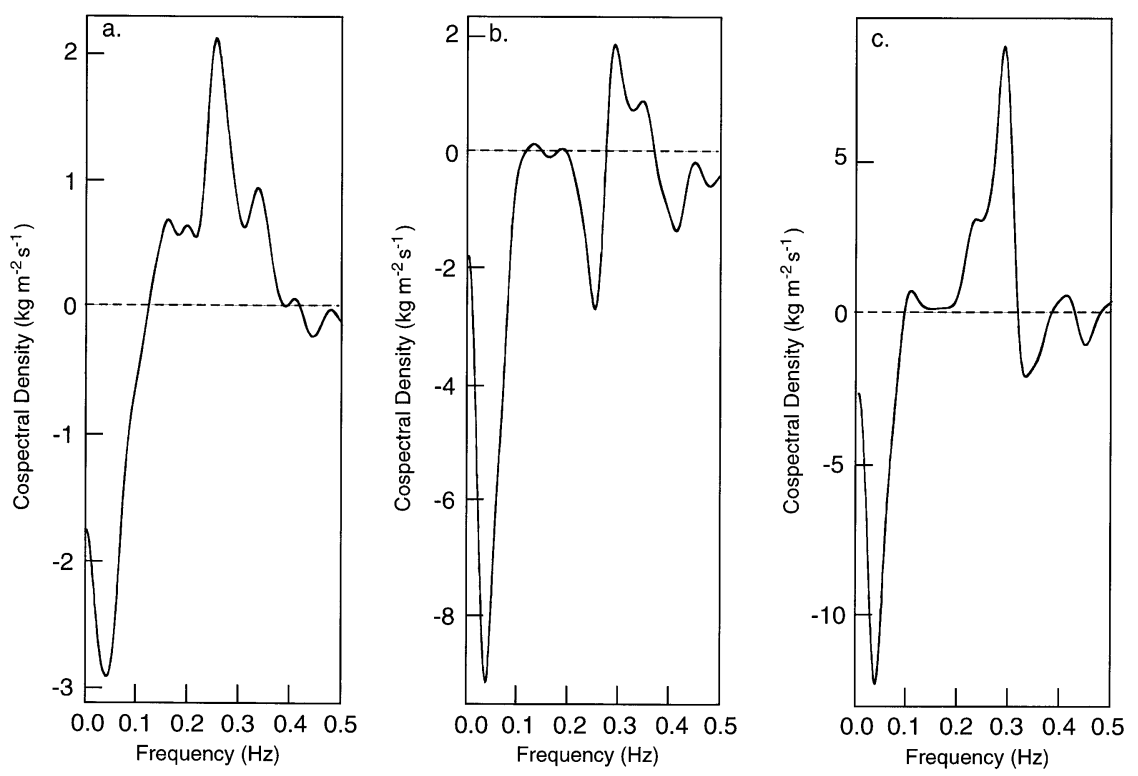

Fig. 7. Cospectra of velocity and concentration at $z=0.04 \mathrm{~m}$ under: (a) symmetrical wave groups with $H_{\mathrm{s}}=0.7 \mathrm{~m}, T_{\mathrm{pk}}=3.6 \mathrm{~s}$ (bedforms: $\eta=0.013 \mathrm{~m}, \lambda=0.144, \eta / \lambda=0.09$ ); (b) positive asymmetrical wave groups with $H_{\mathrm{s}}=0.8 \mathrm{~m}, T_{\mathrm{pk}}=3.5 \mathrm{~s}$ (bedforms: $\eta=0.013 \mathrm{~m}, \lambda=$ $0.140, \eta / \lambda=0.09$ ); (c) negative asymmetrical wave groups with $H_{\mathrm{s}}=0.8 \mathrm{~m}, T_{\mathrm{pk}}=3.5 \mathrm{~s}$ (bedforms: $\eta=0.026 \mathrm{~m}, \lambda=0.320, \eta / \lambda=0.008$ ).

however, the elevation at which this occurs is clearly dependent upon the energy level of the velocity field and the bedform dimensions. The group-bound, long wave generated an up-wave transport at all elevations. Transport rates at this lower frequency also decreased with elevation, although not as rapidly as those for the primary waves; at $z=0.24 \mathrm{~m}$ the net transport signal is again essentially absent. These findings agree both with a number of previous field studies of wave shoaling under irregular, groupy waves (e.g. Osborne and Greenwood, 1992a,b) and with fundamental wave theory (Shi and Larsen, 1981). However, these relationships are modulated not only by elevation above the bed, but also with respect to the position of measurement relative to the bedform geometry.

Bedforms: Fig. 8a illustrates the horizontal velocity spectrum at $z=0.05 \mathrm{~m}$ and the associated co-spectra at $z=0.04-0.24 \mathrm{~m}$, above both a ripple crest (Fig. 8b) and a ripple trough (Fig. 8c). The data were recorded during ripple displacement $(\eta=0.021 ; \lambda=0.193$; $\eta / \lambda=0.11)$ under a single $17 \mathrm{~min}$ simulation of a positive asymmetrical wave group at the highest wave energy. The suspended sediment transport at the primary frequency was directed up-wave above the ripple crest between $z=0.04-0.12 \mathrm{~m}$, and down-wave above the ripple trough at all elevations $(z=0.04-0.28)$. At the lowest elevation $(z=0.04 \mathrm{~m})$ transport measured above the crest was significantly larger (by a factor of four) than transport above the trough. Above the ripple crest transport was reversed above $z=0.12 \mathrm{~m}$ and remained essentially constant. This suggests that vortex- shedding from ripple crests is the dominant mode of suspension on a rippled bed, but that under these conditions this extended only to an elevation of 5-6 ripple heights. The up-wave transport above the crest has been noted previously and reflects the lag in phase coupling associated with the production and then ejection of the larger separation vortex formed in the down-wave lee of the ripple crest (Osborne et al., 1994). Regardless of the measurement position, the low frequency group-bound long wave transport is always directed up-wave (offshore), and is only marginally larger above the ripple crest at all elevations (cf. Fig. 8b and c).

\section{Transport by quasi-steady currents}

The wave-induced, mass transport current due to the shoaling of surface gravity waves was described 

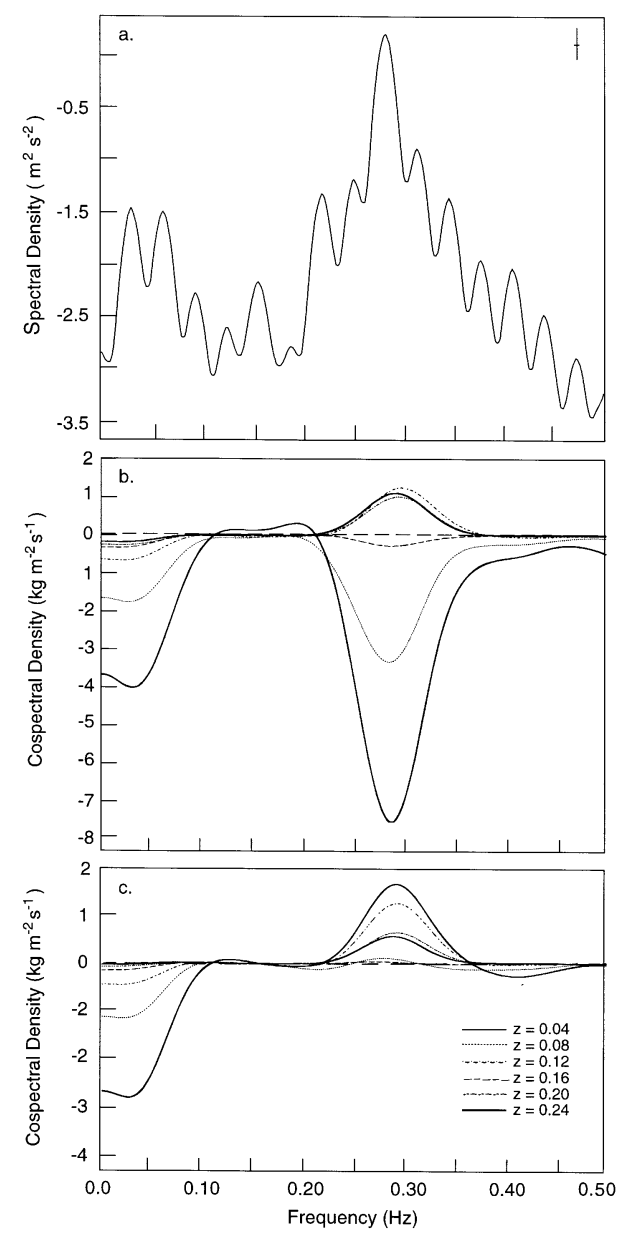

Fig. 8. The horizontal velocity spectrum at $z=0.05 \mathrm{~m}$ (a) and the co-spectra above a ripple crest (b) and ripple trough (c) recorded under negative asymmetrical wave groups. Note: $H_{\mathrm{s}}=0.77 \mathrm{~m}$; $T_{\mathrm{pk}}=3.52 \mathrm{~s}$; bedforms were 3 -dimensional cross-ripples: $\eta=$ $0.027 \mathrm{~m}, \lambda=0.322 \mathrm{~m}, \eta / \lambda=0.084 \mathrm{~m}$.

theoretically by Longuet-Higgins (1953). Assuming a viscous fluid and a finite length of travel of the waves, he proposed that at the top of the wave boundary layer the mean velocity, $U$, would be:

$U=\frac{5}{4} \frac{a^{2} \sigma \kappa}{\sinh ^{2} \kappa h}$,

where $a$ is the wave amplitude $(H / 2), \sigma=2 \pi / T$ ( $T$ the wave period), $\kappa=2 \pi / L$ ( $L$ the wavelength), and $h$ is the still water depth. Although applicable to laminar conditions, Longuet-Higgins also suggested that the above equation could be applied to turbulent flows.

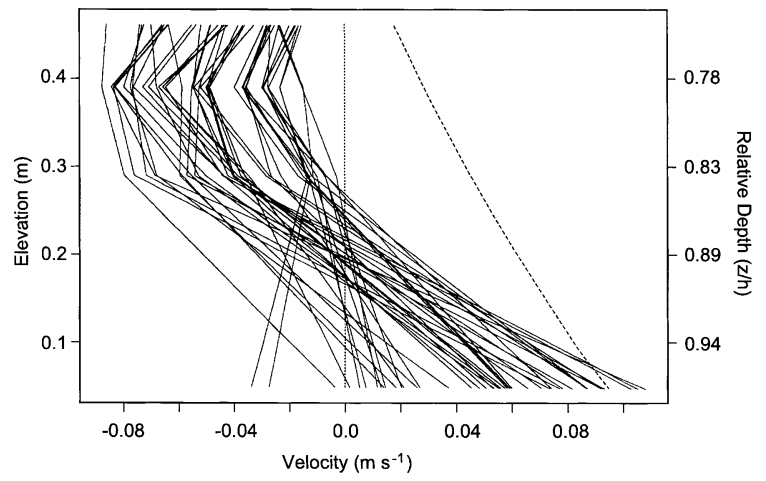

Fig. 9. Drift velocity profiles for the datasets recorded under irregular waves, symmetrical wave groups and positive and negative asymmetrical wave groups. Note: the dotted line is the zero velocity line; the dashed line is the theoretical solution (Longuet-Higgins, 1953) for the average wave condition of this experiment.

The drift within the interior of the fluid, $U$, was:

$$
\begin{aligned}
U= & \frac{a^{2} \sigma \kappa}{4 \sinh ^{2} \kappa h}\{2 \cosh (2 \kappa h(\mu-1)+3 \\
& +\kappa h \sinh \left\{(2 \kappa h)\left(3 \mu^{2}-4 \mu+1\right)\right\} \\
& \left.+3\left(\frac{\sinh 2 \kappa h}{2 \kappa h}+\frac{3}{2}\right)\left(\mu^{2}-1\right)\right\},
\end{aligned}
$$

where $\mu=z / h$ ( $h$ is distance from the surface measured downwards from still water level), and provided that the wave amplitude is small compared with the thickness of wave boundary layer. According to this theory, the drift velocity is directed down-wave both close to the bed and close to the water surface, and up-wave in the middle of the water column. Russell and Osario (1957) verified the solution against laboratory data.

The time-averaged, mean current profile for each data set was determined from five separate current meter measurements taken at elevations of $z=0.05$, $0.29,0.39,0.41$ and $0.46 \mathrm{~m}$. Although the measurements at these elevations were separated by small horizontal distances within the test section, the mean current can reasonably be assumed to be constant at any particular elevation within the section as the flume is essentially 2-dimensional. Fig. 9 illustrates the vertical profile of the mean current for each of the 44 data sets. As expected with relatively small wave 


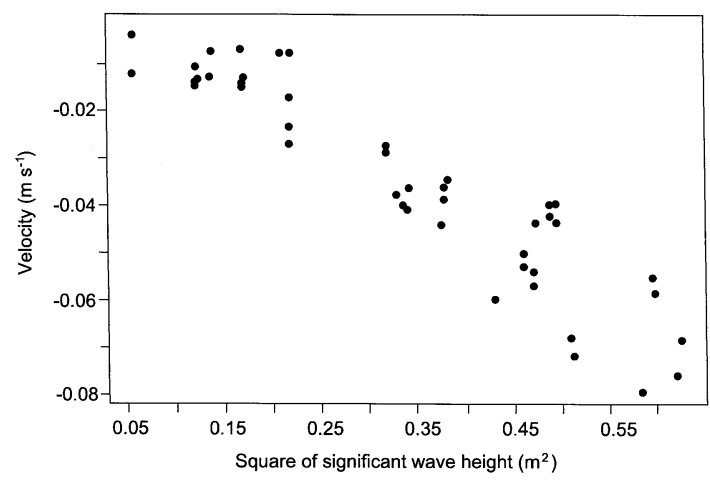

Fig. 10. Relationship between the mean velocity (at $z=0.29 \mathrm{~m}$ ) and the square of significant wave height for all datasets recorded during the experiment.

heights, the mass transport velocities are small $(-0.10<U<0.10 \mathrm{~m})$, and, with few exceptions, the mean current is directed down-wave (positive) close to the bed and decreases upwards and reverses before reaching an elevation of $z=0.24 \mathrm{~m}$. At the highest elevation the mean current decreases again. The up-wave mass transport velocity (at $z=0.29 \mathrm{~m}$ ) is directly proportional to the square of the significant wave height (Fig. 10), which is in agreement with the Longuet-Higgins' solution.

The suspended sediment transport rate associated with the mean current was determined from the cross product between the extrapolated mean velocity and the measured mean concentration. Fig. 11 illustrates the mean transport rate profile integrated over the 44 data sets. As expected, sediment transport by

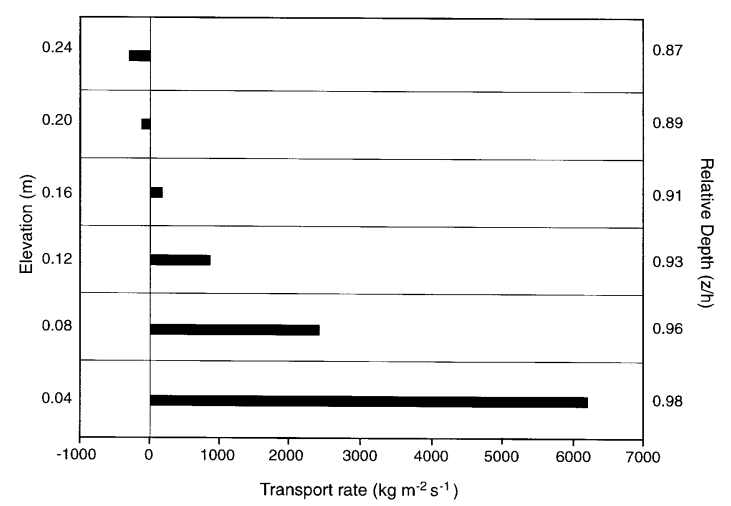

Fig. 11. Profile of the net suspended sediment transport rates integrated over the 44 data sets collected during the experiment. the mean current is directed down-wave close to the bed and up-wave higher in the water column. The average elevation for this reversal occurs around $z=$ $0.18 \mathrm{~m}$; this elevation is approximately $10 \%$ of the water depth $(z / h=0.1)$. This would typify a velocity profile for $\kappa h=1.5$ (see Komar, 1997, page 51).

\section{Net suspended sediment transport}

Fig. 12 illustrates the depth-integrated, net suspended sediment transport rate for all 44 data sets plotted against significant wave height. The graph includes the transport by waves (all frequencies) and by the mean (mass transport) current. The net oscillatory transport rate integrated over 44 data sets was only $+566 \mathrm{~kg} \mathrm{~m}^{2} \mathrm{~s}^{-1}$, compared with the mean flow-induced transport of $+9175 \mathrm{~kg} \mathrm{~m}^{2} \mathrm{~s}^{-1}$. The oscillatory transport rate was therefore only $6 \%$ of the total; waves may entrain large amounts of sediment but the associated net transport is limited because of the opposing transport directions of the high and low frequency components.

As noted earlier, the net sediment transport by the primary waves is directed down-wave and is largest close to the bed. It decreases with elevation and then is directed up-wave at increasing rates above approximately $0.18 \mathrm{~m}$. In contrast, the group-bound long wave transports sediment up-wave at all elevations. In the lower part of the water column, the net transport due to the mean currents and the waves are both directed down-wave. Large amounts of sediment are re-suspended by vortex shedding from the ripple

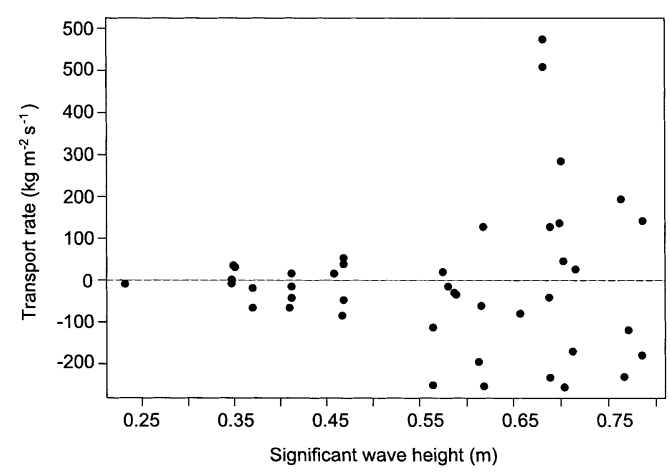

Fig. 12. Scatter plot of the depth-integrated net suspended sediment transport rate against significant wave height for all 44 datasets. 


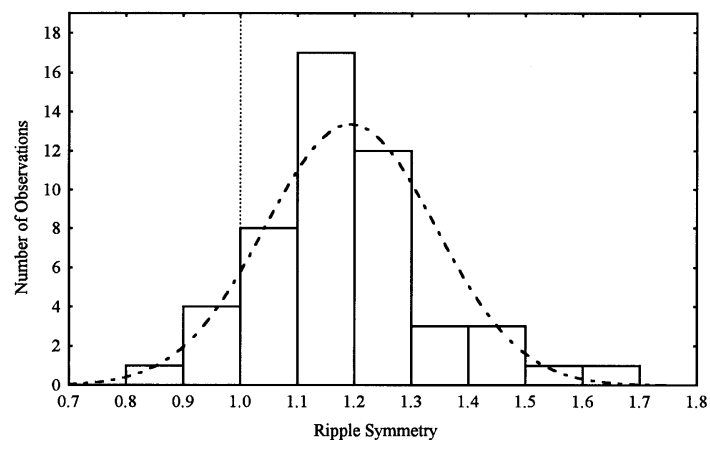

Fig. 13. Distribution of ripple symmetry values for all bedforms measured during the wave simulations. The symmetry index is the ratio between the distances from the ripple crest to the centre of the downwave and upwave troughs respectively. Note: the vertical dashed line represents the value for a perfectly symmetrical ripple form; the mean symmetry index for this dataset was 1.19 . A Gaussian distribution with the same mean and variance has been superimposed.

crests in each half-wave cycle. However, ripple measurements revealed a strong ripple asymmetry under nearly all simulated wave conditions. Fig. 13 illustrates the ripple symmetry index for all bedforms measured under all wave simulations; the symmetry index is the ratio between the distances from the ripple crest to the centre of the downwave and upwave troughs respectively. The distribution is positively skewed and the mean symmetry index is 1.19 ; this indicates that the stoss slope is more gently sloping than the lee slope (perfect symmetry would have an index of unity). This bedform asymmetry is directed down-wave consistent with the near-bed asymmetric oscillatory motion, which exhibits larger average currents directed down-wave. Larger separation vortices would be produced in the down-wave trough and smaller vortices in the up-wave trough. Thus, near the bed, the larger vortices coupled with the larger down-wave oscillatory velocities and the downwave directed mean current results in a large downwave transport of sediment near the bed. As the separation vortices rise higher into the flow, velocity decreases and reverses while the vortex is still coherent, but with decreasing levels of entrained sediment because of settling. When the flow reverses, a second but smaller vortex forms on the up-wave side of the ripples, rises above the bed and is carried upwave near the bed. Near the bed, this up-wave motion is opposed by the mean current, but as the vortex rises it moves into an area where the mean current flows up-wave.

\section{Sediment fractionation}

The samples of suspended sediment revealed that the average grain size decreased upward into the water column from the bed. This vertical fractionation was a response primarily to an enhancement of fines within the size distribution, rather than a significant shift in the modal class. The net horizontal flux of this texturally fractionated suspended load was dominated by transport induced by the time-averaged mean flow, with net oscillatory transports being considerably smaller. The latter reflects the opposing transport induced by the primary, high frequency waves, which transport sand both down-wave and up-wave, depending upon elevation, and the low frequency group-bound long waves which consistently transport sand up-wave at all elevations. The quasi-steady currents are largest close to the bed and directed down-wave; their magnitudes decrease upwards in the lower water column and the currents actually reverse their direction at some elevation. The result is that the net suspended sediment transport rate is down-wave close to the bed, where the size distribution is dominated by coarser fractions, and up-wave at higher elevations, where the percentage of the finer fractions is larger.

Although no measurements were possible below $0.04 \mathrm{~m}$, of either currents or sediment concentrations, it is most probable that the transport here is also dominated by the mean flows. Theoretically, the mass transport should increase further until it reaches a maximum at the top of the wave-boundary layer, and then must decrease to zero at the bed; the sediment concentration, in contrast, should increase continuously toward the bed until it merges with the bedload. The drift velocity at the edge of the wave boundary layer, calculated according to LonguetHiggins (1953), ranged from 0.02 to $0.21 \mathrm{~m} \mathrm{~s}^{-1}$; this compares with values ranging from near zero (i.e. within the confidence band of the current sensor) to $0.11 \mathrm{~m} \mathrm{~s}^{-1}$ measured at $z=0.05 \mathrm{~m}$.

It should be noted that horizontal diffusion could (at least in theory) cause suspended sediment to be 
transported both down-wave and up-wave, since concentrations vary horizontally as well as vertically. However, over the sand pad the direction of this flux might be assumed to be random, with no net transport. It is possible that this type of process could be particularly strong at the margins of the sand pad at the junction with the bare flume bed, but the overall rates would still be relatively small. Simple diffusion of suspended sediment would move the finer fractions further away from the test section as they take more time to settle. Thus, the decrease of sediment size in up-wave direction may be enhanced. However, this did not obliterate the increase in the coarse fraction in the down-wave direction. The increase of sediment size down-wave may be caused by the almost in-phase movement of sediment-laden vortices with respect to the associated oscillation. Xu (1998) used collocated measurements of concentration $(0.04 \mathrm{~m}$ above the bed) and velocity $(0.05 \mathrm{~m}$ above the bed) to show that sediment-laden separation vortices can be released before flow reversal due to the inverse momentum gradient. The phase difference between concentration and velocity will decrease as the bed is approached. Thus, the up-wave transport induced by waves would decrease and the down-wave transport would be more dominant. Therefore, the decrease of the up-wave transport and the increase of downwave transport by mean currents below $z=0.04 \mathrm{~m}$ would move coarser sediment down-wave. The experiment documented here is a case with a rippled bed. Ribberink and Al-Salem (1995) described an experiment with a flat bed and sheet flow conditions. It was also found that the total net transport was directed down-wave below an elevation of $0.05 \mathrm{~m}$, and there was a small net sediment flux directed upwave above $0.05 \mathrm{~m}$.

Bedload transport could not be measured in the present experiment and it is not certain what influence it has on the fractionation process. However, direct observation revealed that the process of vortex ejection from ripple troughs and vortex advection was dominant in the transport process. Bedforms did not simply migrate away from the test section, either downwave or upwave. The ripples that formed outside the test section, did so as 'starved' two-dimensional ripples initially; they did however cover a significant section of the floor of the flume. It is unlikely therefore that bedload transport (at least as indicated by ripple migration) contributed significantly to the total transport, and thus equally unlikely that it was responsible for the horizontal fractionation of grain size.

\section{Discussion and conclusions}

Under the simple conditions of wave shoaling over a near-horizontal, rippled bed, it is clear that a distinct fractionation of sediment by size can occur by suspension transport alone. Sediments became progressively coarser down-wave from the source and progressively finer up-wave from the same source. This spatial sorting by size was associated with two factors: (a) a vertical profile of the mean mass transport velocity, which revealed a down-wave (onshore) directed current close to the bed and a current reversal at higher elevations. The average elevation for the reversal was $0.14 \mathrm{~m}$ under the range of wave conditions simulated $\left(H_{\mathrm{s}}=0.22-0.78 \mathrm{~m} ; T_{\mathrm{pk}}=2.25-\right.$ $3.78 \mathrm{~s}$ ); (b) a vertical profile of grain-size in the sediment suspended above the bed, in which there was a distinct increase in the proportion of fines with elevation and a decrease in the mean size by approximately $18 \%$ between 0.04 and $0.24 \mathrm{~m}$. Thus, suspended sediment transport would result in coarser materials moving downwave close to the bed and finer sediments moving upwave at higher elevations. These two factors were enhanced by a frequency-dependent transport by the wave field. The primary waves produced a maximum transport of suspended sediment close to the bed directed down-wave The rapid decay in concentration with elevation combined with the decoupling between concentration and velocity with elevation associated with the primary waves, meant that the net suspended transport decreased rapidly with elevation. In contrast the net transport associated with the lower frequency, group-bound, long wave was directed up-wave (offshore) at all elevations and the decay rate was significantly less than that associated with the primary waves. Thus, while the near bed transport by the primary and secondary waves was roughly equal and opposite (resulting in little wave-induced net transport close to the bed), at higher elevations the up-wave transport by the secondary wave was dominant. The latter would complement the transport due to the mass transport current at higher elevations. 


\section{Acknowledgements}

This research was carried out as part of the Canadian Coastal Sediment Transport Programme (C-COAST) supported by Strategic, Operating and Equipment Grants from NSERC. The Institute for Engineering in the Canadian Environment, National Research Council Canada, supported the laboratory experiment; we acknowledge the assistance of D.H. Willis, M. Davies, E.P.D. Mansard and M.D. Miles from the Institute. Dr P.D. Osborne, (now with Pacific International Engineering), coordinated the experiments and Carl Boldy (UTSc) provided invaluable assistance in data acquisition and data transfer. Drs C. Vincent, M. Webb and S. Marsh (University of East Anglia) helped with the measurements during the 3 weeks of laboratory work. We thank Dr Piet Hoekstra, Dr Kerry Black and an unknown reviewer for materially improving the manuscript.

\section{References}

Bagnold, R.A., 1940. Beach formation by waves: some model experiments in a wave tank. J. Inst. Civil Engng 15, 27-52.

Black, K.P., Rosenberg, M.A., 1994. Suspended sand measurements in a turbulent environment: field comparison of optical and pump sampling techniques. Coastal Engng 24, 137-150.

Cornaglia, P., 1898. On beaches. Accadamia Nazionale dei Lincei Atti, Classe di Scienze Fisiche, Matematiche e Naturali, Mem. 5, Ser. 4: 284-304. Reproduced in translation. In: Fisher, J.S., Dolan, R. (Eds.), Beach Processes and Coastal Hydrodynamics. Benchmark Papers in Geology, Stroudsberg, PA, $39,11-26$.

Cornish, V., 1898. On sea beaches and sand banks. Geogr. J. 11, 528-559 (see also pages 628-647).

Davidson, M.A., Russell, P.E., Huntley, D.A., Hardisty, J., 1993. Tidal asymmetry in suspended sand transport on a macro-tidal beach. Mar. Geol. 110, 333-353.

Davies, M.H., Laurich, P.H., Mansard, E.P.D., Miles, M.D., 1994. A new wave research flume at NRC. Proc., International Symposium on Waves Numerical Modeling, pp. 166-174.

Downing, J.P., Sternberg, R.W., Lister, C.R.B., 1981. New instrumentation for the investigation of sediment suspension processes in shallow marine environments. Mar. Geol. 42, $19-34$.

Fairchild, J.C., 1977. Suspended sediment in the littoral zone at Ventnor, New Jersey and Nags Head, North Carolina. US Army Corps of Engineers, CERC Tech. Pap. 77-5, 97 pp.

Fox, W.T., Ladd, J.W., Martin, M.K., 1966. A profile of the four moment measures perpendicular to a shoreline, South Haven, Michigan. J. Sedim. Petrol. 36, 1126-1130.

Funke, E.R., Crookshank,N.L., Wingham, M., 1980. An introduc- tion to GEDAP - an integrated software system for experimental control, data acquisition and data analysis. Technical Report LTR-HY-75, Institute of Mechanical Engineering, NRC, Canada.

Grant, W.D., Madsen, O.S., 1979. Combined wave and current interaction with a rough bottom. J. Geophys. Res. 84, 17971808.

Grant, W.D., Madsen, O.S., 1982. Movable bed roughness in unsteady oscillatory flow. J. Geophys. Res. 87, 469-481.

Green, M.O., Black, K.P., 1999. Suspended-sediment reference concentration under waves: field observations and critical analysis of two predictive models. Coastal Engng 38, 115-141.

Greenwood, B., 1969. Sediment parameters and environment discrimination: an application of multivariate statistics. Can. J. Earth Sci. 6, 1347-1357.

Greenwood, B., Davidson-Arnott, R.G.D., 1972. Textural variation in the sub-environments of the shallow-water wave zone, Kouchibouguac Bay, New Brunswick. Can. J. Earth Sci. 9, 679-688.

Greenwood, B., Jagger, K., 1995. Sensitivity of optical sensors to grain-size variation in the sand mode: implications for transport measurements. Proceedings 1995 Canadian Coastal Conference, Dartmouth, Canadian Coastal Science and Engineering Association, NRC, Ottawa, pp. 383-398.

Greenwood, B., Osborne, P.D., Bowen, A.J., Hazen, D.G., Hay, A.E., 1990. C-COAST: the Canadian Coastal Sediment Transport Programme. Suspended sediment transport under waves and currents. Proc., Canadian Coastal Conference, Kingston, Ont., NRCC Assoc. Comm. Shorelines, pp. 319-336.

Greenwood, B., Osborne, P.D., Bowen, A.J., Hazen, D.G., Hay, A.E., 1991. Nearshore sediment flux and bottom boundary dynamics: the Canadian Coastal Sediment Transport Programme (C-COAST). Proceedings of 22nd International Conference on Coastal Engineering, Delft, The Netherlands, ASCE, New York, pp. 2227-2240.

Greenwood, B., Richards, R.G., Brander, R.W., 1993. Acoustic imaging of sea-bed geometry and dynamics: a high resolution remote tracking sonar (HRRTS II). Mar. Geol. 112, 207-218.

Greenwood, B., Boldy, C.D., Atkins, R.J., 1995. A simple algorithm to assess the coupling between sediment suspension and fluid velocity under irregular waves. Proceedings Canadian Coastal Conference, Dartmouth, pp. 371-382.

Guillen, J., Hoekstra, P., 1996. The equilibrium distribution of grain size fractions and its implications for cross-shore sediment transport: a conceptual model. Mar. Geol. 135, 15-33.

Guillen, J., Hoekstra, P., 1997. Sediment distribution in the nearshore zone: grain size fractions in response to shoreface nourishment (Island Teschelling, the Netherlands). Estuarine, Coastal Shelf Sci. 45, 639-652.

Hanes, D.M., 1991. Suspension of sand due to wave groups. J. Geophys. Res. 96, 8911-8915.

Hoekstra, P., Houwman, K.T., 1998. Selective sediment transport in the nearshore zone: field observations and potential mechanisms. Proceedings Coastal Dynamics '97, Plymouth, UK, pp. $78-87$.

Horn, D.P., 1992. A numerical model for shore-normal sediment 
size variation on a macro-tidal beach. Earth Surf. Process. Landforms $17,755-773$.

Huntley, D.A., Hanes, D.M., 1987. Direct measurements of suspended sediment transport. Coastal Sediments'87. ASCE, New York, pp. 723-737.

Inman, D.L., 1953. Areal and seasonal variations in beach and nearshore sediments at La Jolla, California. US Army, Corps of Engineers, Beach Erosion Board, Tech. Memo., 34, 82 pp.

Ippen, A.T., Eagleson, P.S., 1955. A study of sediment sorting by waves shoaling on a plane beach. US Army Corps of Engineers, Beach Erosion Board, Tech. Memo., No. 63, 83 pp.

Jamieson, W.W., Mansard, E.P.D., 1989. An efficient upright wave absorber. Proceedings of ASCE Speciality Conference on Coastal Hydrodynamics, ASCE, New York.

Johnson, J.W., Eagleson, P.S., 1966. Coastal Processes. In: Ippen, A.T. (Ed.), Estuary and Coastal Hydrodynamics. McGraw-Hill, New York, pp. 404-492.

Jonsson, I.G., 1966. Wave boundary layers and friction factors. Proceedings of 10th International Conference on Coastal Engineering, Tokyo, ASCE, New York, pp. 127-148.

Kana, T., 1979. Suspended sediment in breaking waves. University of South Carolina, Columbia, SC, Dept. Geol. Tech. Rept. 18CRD, 153 pp.

Kennedy, S.K., Ehrlich, R., Kana, T.W., 1981. The non-normal distribution of intermittent suspension sediments below breaking waves. J. Sedim. Petrol. 51, 1103-1108.

Keulegan, G.H., 1948. An experimental study of submarine sand bars. US Army Corps of Engineers, Beach Erosion Board, Tech. Rept. No. 5.

Komar, P.D., 1997. Beach Processes and Sedimentation. 2nd ed. Prentice-Hall, Englewood Cliffs, NJ.

Kraus, N., 1987. Application of portable traps for obtaining point measurements of sediment transport rates in the surf zone. J. Coastal Res. 2, 139-152.

Lee, T.H., Hanes, D.M., 1996. Comparison of field observations of the vertical distribution of suspended sand and its prediction by models. J. Geophys. Res. 101 (C2), 3561-3572.

Longuet-Higgins, M.S., 1953. Mass transport in water waves. Phil. Trans. R. Soc. London 245A, 535-581.

Longuet-Higgins, M.S., 1956. The mechanics of the boundary-layer near the bottom in a progressive wave. Proceedings of 6th Conference on Coastal Engineering, Miami, ASCE, New York, pp. 184-193.

McManus, D.A., 1963. A criticism of certain usage of the phi notation. J. Sedim. Petrol. 33, 670-674.

Miles, M.D., 1990. The GEDAP Data Analysis Software Package. Tech. Rept. TR-HY-030, NRC No. 32086, National Research Council Canada, Institute for Mechanical Engineering, Hydraulics Laboratory, $88 \mathrm{pp}$.

Miller, R.L., Zeigler, J.M., 1958. A model relating dynamics and sediment pattern in equilibrium in the region of shoaling waves, breaker zone and foreshore. J. Geol. 66, 417-441.

Miller, R.L., Zeigler, J.M., 1964. A study of sediment distribution in the zone of shoaling waves over complicated bottom topography. In: Miller, R.L. (Ed.), Papers in Marine Geology Shepard Commemorative Volume. MacMillan, New York, pp. 133-153.
Mothersill, J.S., 1969. A grain size analysis of longshore bars and troughs, Lake Superior, Ontario. J. Sedim. Petrol. 39, 13171324.

Murray, S.P., 1967. Control on grain dispersion by particle size and wave state. J. Geol. 75, 612-634.

Niederoda, A.W., Swift, J.P., Hopkins, T.S., 1985. The Shoreface. In: Davis Jr., R.A. (Ed.), Coastal Sedimentary Environments. Springer, New York, pp. 533-624.

Nielsen, P., 1983. Entrainment and distribution of different sand sizes under water waves. J. Sedim. Petrol. 53, 423-428.

Nielsen, P., 1992. Coastal Bottom Boundary Layers and Sediment Transport. Adv. Ser. Ocean Engng, vol. 4. World Scientific, Singapore, $324 \mathrm{pp}$.

Ollerhead, J.W., Greenwood, B., 1990. Bedform geometry and dynamics in the upper shoreface, Bluewater Beach, Ontario, Canada. Proceedings, Canadian Coastal Conference 1990, Kingston, Ont., NRCC Associate Comm. on Shorelines, Ottawa, pp. 337-348.

Osborne, P.D., Greenwood, B., 1992a. Frequency dependent crossshore suspended sediment transport. 1. A non-barred shoreface. Mar. Geol. 106, 1-24.

Osborne, P.D., Greenwood, B., 1992b. Frequency dependent crossshore suspended sediment transport. 2. A barred shoreface. Mar. Geol. 106, 25-51.

Osborne, P.D., Greenwood, B., 1993. Sediment suspension under waves and currents: time scales and vertical structure. Sedimentology 40, 599-622.

Osborne, P.D., Vincent, C., Greenwood, B., Marsh, S., Webb, M., Boldy, C., Jagger, K., Zhiming, X., 1994. Sediment suspension and transport under irregular waves: roughness control on the re-suspension and transport of sediment. Waves — Physical and Numerical Modelling, Proceedings of International Symposium, Vancouver, IAHR, Vancouver, pp. 1617-1626.

Ribberink, J.S., Al-Salem, A.A., 1995. Sheet flow and suspension of sand in oscillatory boundary layers. Coastal Engng 25, 205225.

Richards, R.G., Greenwood, B., 1993. An acoustic sensor for measuring bedform geometry and dynamics. Proceedings of Canadian Coastal Conference, Vancouver, CC-SEA, NRCC, Ottawa, pp. 557-569.

Russell, R.C.H., Osario, J.D.C., 1957. An experimental investigation of drift profiles in a closed channel. Proceedings of 6th Coastal Engineering Conference, ASCE, New York, pp. 171-183.

Shi, N.C., Larsen, L.H., 1981. Reverse sediment transport induced by amplitude modulated waves. Mar. Geol. 54, 181-200.

Skafel, M.G., Krishnappan, B.G., 1984. Suspended sediment transport distribution in a wave field. J. Waterway, Port, Coastal, Ocean Engng Div., ASCE 110, 215-230.

Sternberg, R.W., Shi, N.C., Downing, J.P., 1989. Continuous measurements of suspended sediment. In: Seymour, R.J. (Ed.), Nearshore Sediment Transport. Plenum Press, New York, pp. 231-257.

Syvitski, J.P.M. (Ed.), 1991. Principles, Methods and Application of Particle Size Analysis. Cambridge University Press, Cambridge, 368 pp.

Vincent, C.E., Green, M.O., 1990. Field measurements of the suspended sand concentration profiles and fluxes and of the 
re-suspension coefficient $(\gamma)$ over a rippled bed. J. Geophys. Res. 95, 11591-11601.

Wang, P., Davis Jr, R.A., Kraus, N., 1998. Cross-shore distribution of sediment texture under breaking waves along low wave energy coasts. J. Sedim. Petrol. 68, 497-506.

Williams, J.J., Bell, P.S., Thorne, P.D., Trouw, K., Hardcastle, P.J.,
Humphery, J.D., 2000. Observed and predicted vertical suspended sediment concentration profiles and bedforms in oscillatory only flow. J. Coastal Res. 16, 698-708.

Xu, Z., 1998. Sediment suspension under groupy waves. Unpublished PhD Thesis, University of Toronto, 216 pp. 